\title{
Safe surgeries: elaboration and validation of a checklist for outpatient surgical procedures
}

\author{
Cirurgia segura: construção e validação de um checklist \\ para procedimento cirúrgico ambulatorial \\ Cirugía segura: elaboración y validación de una checklist \\ para intervención quirúrgica en enfermería \\ Thaís Aparecida Porcaria \\ Paula Cristine Figueiredo Cavalarib \\ Alessandra Nazareth Cainé Pereira Roscani ${ }^{b}$ \\ Ana Railka de Souza Oliveira Kumakurac \\ Renata Cristina Gasparinoc
}

How to cite this article: Porcari TA, Cavalari PCF, Roscan ANCP, Kumakura ARSO, Gasparino RC. Safe surgeries: elaboration and validation of a checklist for outpatient surgical procedures. Rev Gaúcha Enferm. 2020;41:e20190321. doi: https://doi. org/10.1590/1983-1447.2020.20190321 a Irmandade da Santa Casa de Misericórdia de Valinhos. Valinhos, São Paulo, Brasil.

${ }^{\circ}$ Universidade Estadual de Campinas (UNICAMP), Hospital de Clínicas. Campinas, São Paulo, Brasil.

'Universidade Estadual de Campinas (UNICAMP), Faculdade de Enfermagem. Campinas, São Paulo, Brasil.

\section{ABSTRACT}

Purpose: To prepare and validate the content of a checklist in order to assure the safety for outpatient surgical procedures.

Method: Methodological research, performed between May and December 2018, as per three stages: 1) preparation of the checklist; 2) validation of content by five judges; and 3) preliminary testing of the instrument. The concord, among the judges, was measured by the Content Validity Index and the values over 0.9 were considered as being satisfactory.

Results: Initially the instrument was prepared having 58 items, considering the heading and six topics. In the first round, two topics and 27 items had an index below 0.9. After reformulations, in the second round, only two items had values below 0.9 and, in the third, all items reached an index of 1.0. Along the preliminary testing, modifications were realized. The final version it has 43 items, distributed as per five topics.

Conclusion: The "Checklist for Safe Surgery regarding Ambulatory Surgical Procedures" was prepared and its contents were validated. Keywords: Patient safety. Validation studies. Checklist. Ambulatory surgical procedures.

\section{RESUMO}

Objetivos: Construir e validar o conteúdo de um checklist de verificação de segurança específico para procedimentos cirúrgicos ambulatoriais.

Método: Pesquisa metodológica, realizada entre maio e dezembro de 2018, em três etapas: 1) construção do checklist; 2) validação do conteúdo por cinco juízes e 3) pré-teste do instrumento. A concordância entre os juízes foi mensurada pelo Índice de Validade de Conteúdo e valores acima de 0,9 foram considerados satisfatórios.

Resultados: Inicialmente 58 itens foram distribuídos entre 0 cabeçalho e seis tópicos. Na primeira rodada, dois tópicos e 27 itens obtiveram índice inferior a 0,9. Após reformulações, na segunda rodada, somente dois itens obtiveram valores inferiores a 0,9 e, na terceira, todos os itens alcançaram índice de 1,0. No pré-teste, outras pequenas alterações foram realizadas. A versão final possui 43 itens, distribuídos em cinco tópicos.

Conclusão: 0"Checklist de Cirurgia Segura para Procedimento Ambulatorial"foi construído e teve o seu conteúdo validado. Palavras-chave: Segurança do paciente. Estudos de validação. Lista de checagem. Procedimentos cirúrgicos ambulatórios.

\section{RESUMEN}

Objetivo: Elaborar y validar el contenido de una checklist para garantizar la seguridad en la realización de intervenciones quirúrgicas en enfermería.

Método: Pesquisa metodológica, realizada entre mayo y diciembre de 2018, en tres etapas: 1) elaboración de la checklist; 2) validación de contenido por cinco jueces; y 3) comprobación preliminar del instrumento. La concordancia entre los jueces fue medida por el Índice de Validez de Contenido y valores superiores a 0,9 fueron considerados satisfactorios.

Resultados: Inicialmente se distribuyeron 58 ítems entre el encabezado y seis temas. En la primera ronda, dos temas y 27 ítems tenían un índice inferior a 0.9. Después de las reformulaciones, en la segunda ronda, solo dos ítems tenían valores inferiores a 0.9 y, en la tercera, todos los ítems alcanzaron un índice de 1.0. En la comprobación preliminar, se hicieron modificaciones. La versión final tiene 43 ítems, distribuidos en cinco temas.

Conclusión: La"Checklist de Cirugía Segura para Intervención Quirúrgica en Enfermería" fue elaborada y tuvo su contenido validado. Palabras clave: Seguridad del paciente. Estudios de validación. Lista de verificación. Procedimientos quirúrgicos ambulatórios. 


\section{INTRODUCTION}

In 1999, the United States Institute of Medicine (IOM) published the report "To err is human", in which it revealed that there are from 44,000 to 98,000 deaths every year due to errors committed in hospital healthcare ${ }^{(1)}$. These results motivated a worldwide movement according to which patient safety should be treated as a fundamental principle of all health systems ${ }^{(2)}$.

As a result, in 2004, the World Health Organization (WHO) published the World Alliance for Patient Safety, which has six priority strategies: the correct identification of the patient; improvements in the effective communication between health professionals; improvements in the elaboration of prescriptions, the dispensing and administration of medications; hand hygiene; evaluation of patients regarding their risk of falling, pressure lesions, as well as safety in surgeries, including measures related to verifying the correct patient, pre-operative evaluations, hospitalizations, correct surgical sites, and preparing for adequate post-operative care ${ }^{(3)}$.

The "Safe Surgeries Save Lives" program, a detailed proposal by the WHO in 2008, includes ten essential objectives for surgeries that involve checking whether the patient and the site of the surgery are the correct ones, whether the team is prepared to prevent damages that may result from the administration of anesthetic medication, as well as for airway management, blood loss, infections, compression bandage and/or instrument retention, and transferal of surgical specimens, as well as checking if effective communication should be implemented ${ }^{(2)}$.

The program presents verification lists and checklists to verify whether these objectives are being met. These aid in the verification of essential elements related to the safety of the patient during the realization of a surgical procedure. The checklist proposed by the WHO is divided in three topics: 1 . Sign in; 2. Time out; and 3. Sign out.

Due to these national and international discussions, the Brazilian Ministry of Health instituted, in 2013, the National Program for Patient Safety (PNSP), which aimed at contributing to qualify healthcare in all health institutions in national territory. Among its strategies, are the elaboration and support to the implementation of protocols, and patient safety manuals and guidelines, exemplified by the Surgical Safety Verification List ${ }^{(4)}$.

Studies have shown that, despite the barriers posed by professionals for the implementations of checklists, they significantly increased the odds of patients receiving adequate surgical treatment ${ }^{(5-6)}$. However, considering the worldwide estimates that one in every 25 people will undergo surgical treatments that can lead to serious complications, the relevance becomes clear of implementing verification lists to minimize these avoidable situations ${ }^{(7)}$.

However, it should be highlighted that existing Verification Lists do not attend to the specificities of outpatient surgical procedures, which are carried out using any type of anesthesia and require no hospitalization, allowing the patient to be back home in, at most, 24 hours $^{(8)}$.

The number of outpatient surgeries has been growing due to the invention of new anesthetic methods and the numerous benefits brought by them, such as minimum changes in the patients' routine, diminished risk of hospital infections, less physical disability, faster return to daily life activities, diminution in morbidity and mortality rates, increased availability of hospital beds, and lower prices ${ }^{(8)}$. That is why specific checklists for procedures in these environments is essential, and they should be available to guarantee the safety of the patient ${ }^{(9-10)}$.

Studies have shown that the use of checklists in the surgical environment allows for positive results for the patients, professionals and institutions, such as: diminution of complications and mortality, improvements in the communication between health professionals, teamwork, and cost reduction ${ }^{(6,11-12)}$.

Therefore, and considering that the implementation of the checklists for safe surgeries should be adapted to each service, depending on its complexity, and that the WHO checklist does not include questions specific to outpatient procedures, such as criteria for admitting patients, conducting the procedure, and discharging patients $s^{(8)}$, the question that guided this research was: are there validated instruments to verify the safety of patients who undergo outpatient surgical procedures?

Due to the absence in literature of specific checklists for the context being studied, this study aimed to elaborate and validate the contents of a specific checklist to verify the safety of outpatient surgical procedures.

\section{$\square$ METHOD}

Methodological research, with a mixed-method approach, developed from May to December 2018 in three stages. In the first stage, the checklist was elaborated based on the WHO instrument and on the scientific literature on the subject(2,4,8).

In the second stage, the contents of the instrument were submitted to the evaluation of a group of judges. Authors recommended this group to be made of, at least, five people with clinical experience, publications and experience on the theme, and knowledge about the conceptual structure being addressed ${ }^{(12)}$. The validity of the content makes it possible to 
examine how much each item in an evaluation instrument is relevant and representative of the theme being studied, its response options and the instructions provided ${ }^{(13-14)}$.

For the content validation stage, the judges were selected in a non-probabilistic manner, according to the following inclusion criteria: having theoretical, practical and/or research experience in surgical centers and/or patient safety. The study excluded those who took more than 30 days to send back the materials with the answers.

Each judge received, through e-mail, the Consent Form to Participate in the Research, the instructions to evaluate the validity of the content, and the checklist. The analysis of the judges and the clarity and pertinence of the topics was carried out using the Delphi technique, through a Likert scale with four points, being them: one (the item is not relevant or not representative), two (the item needs large revisions to become relevant or representative), three (the item needs minor revisions to become relevant or representative), and four (the item is relevant and representative) ${ }^{(13)}$. When options one or two were chosen, the judges should suggest changes or the exclusion of the items ${ }^{(14)}$.

After the evaluation of judges, in each round, the answers were tabulated in the software Microsoft Excel for Windows ${ }^{\circledR}$ and the Content Validity Index (CVI) was calculated, to verify the percentage of agreement between the judges with regards to the content being evaluated ${ }^{(13)}$. To evaluate the agreement, the answers three and four attributed by the judges to each topic/item were added up and divided by the total number of responses. When the agreement between the judges was below 0.9, the item was reformulated by the researchers, based on the suggestions presented, and then sent again to the group for another evaluation, until a consensus was reached ${ }^{(14)}$. Three rounds were needed to reach the final version of the checklist. In addition to this quantitative stage, all suggestions or comments were analyzed to improve the clarity of the items/topics evaluated.

After validation from the group of judges, the instrument was submitted to the third stage: the pre-test. The sample was defined by the availability and participation acceptance of nursing professionals working in the Outpatient Surgical Center in a public teaching hospital in Campinas, São Paulo, Brazil. All those who offered direct assistance to the patient and were present during the data collection period were included. Those who were on vacation and/or leave were excluded.

This stage aimed to verify whether the items in the checklist were understood by the population who would use them. The suggestions of the participants were also analyzed to make the instrument even easier to understand. At the end of this stage, there were alterations in the instruments that the researchers thought were important, and, therefore, the judges from the previous stage were again contacted. Only three of them accepted examining the new version ${ }^{(14)}$.

The study was submitted to the appreciation of and approved by the Research Ethics Committee of the University of Campinas, and its execution was authorized under protocol No. 2.482.722, according to Resolution 466/12. It followed all ethical principles for clinical researches involving human beings.

\section{RESULTS}

The instrument, at first, was elaborated following the processes carried out in the Outpatient Surgical Centers, as were the essential objectives for surgical safety, and was made up of items distributed between the Heading (seven items) and six topics: Reception (seven items); Preparation room (eight items); Medical evaluation (five items); Before anesthesia and sterile field distribution (thirteen items); Before leaving the operating room (eight items); and Before leaving the surgical center (ten items).

The heading includes the identification of the patient, the date, the time, and the procedures proposed. The Reception topic included items such as the presence of a document with photo, medical records, tags, identification bracelets, and signed consent forms. In the Preparation room part, the questions involved the existence of allergies and the confirmation of the patient with regards to the procedure, the surgical site/side of the surgery, and their vital signs.

In the Medical evaluation, the items to be checked involve marking the correct side, the presence of exams, the type of anesthesia, and the existence of pre-anesthetic evaluations. The topic Before anesthesia and field distribution included items such as the representation of the team, the confirmation of the procedure and the surgical site, checking whether the equipment is working and the expiration dates of materials.

The topic Before leaving the operating room includes questions such as sending specimens to anatomical pathology, instrument counting, compress bandage and needles need to be checked. Finally, Before leaving the surgical center evaluates items such as the referral of the patient and the presence of medical prescriptions, sick notes, summary, and discharge guidance should.

Nine judges were invited to the validation stage, but only five accepted participating in this research. Three were PhD in the field of medical-surgical nursing and Professor in a state university; one was a PhD in health sciences and the current coordinator of the center for Patient Safety in a large public hospital; and one was the nursing supervisor of 
the surgical center of the same hospital. Three rounds were needed for all items/topics to reach a CVI above 0.9. The judges took, on average, 17 days to answer in each round.

In the first round, the judges evaluated all topics and items, suggested the addition of seven extra items and an alteration in the order in which the items were presented. In the possible answers to the question "Does the patient inform the side" the options "left" and "right" were excluded, and only the options "Yes", "No", and "N/A" (does not apply) were maintained. The question "Does the patient inform which surgery will be carried out?" was added, with the options "No", "Yes", and the field "Specify".

Also, in this round, some items underwent changes in the scale of answers, since they reached CVIs below the values stipulated. As an example, in addition to the options "female" and "male", "not informed" was added to the field "sex".

In four items, such as the removal of prosthesis and ornaments, the counting of compress bandage and needles, and the delivery of discharge summaries, the option "N/A" was added as a response. In the item "Origin", the following response options were added in the second round:"residency", "nursing ward", and "bed".

Table 1 shows the topics Reception and Medical Evaluation and 27 items that did not meet the minimum 90\% agreement, and, as a result, were changed after a descriptive analysis of the suggestions of the judges.

After reformulations, the topic "Reception" was changed into "Patient admission" and the topics"Medical evaluation" and "Before anesthesia and distribution of sterile fields" were grouped and renamed as "Before the start of the surgery/procedure".

The 27 items were also reformulated according to the suggestion of the judges. Among them, only two did not reach the CVI determined in the second round: "Are identification tags present and correct?" and "Were prostheses and ornaments given to the person accompanying the patient?". As a result, these were reformulated again and, in the third round, these three items were divided into three: "Are identification tags present?", "Are identification tags correct?", and "If yes, were prostheses and ornaments given to the person accompanying the patient?"

Therefore, after the three rounds were carried out, the version of the instrument for the pre-test was obtained. It was made up of items distributed in five topics: Heading (11 items); Patient admission (8 items); Preparation room (10 items); Before the start of the surgery/procedure (15 items); Before leaving the operating room (11 items); and Before leaving the surgical center ( 9 items).

In this stage, 17 nurses participated (70.8\% of the population) and suggested many changes in the instrument, which included: a) formatting (sequential numbering of items); b) the exclusion of some words, such as changing "Does the patient have a photo ID?" into "Is a photo ID present?"; c) transforming three items in one item with subdivisions: "Does the team verbally confirm the name of the patient, the procedure, and the site"; d) changes in the topic in which items were initially inserted, such as the items that address the presence of exams, pre-anesthetic visits, and skin lesions, which were transferred from the topic Before the start of the surgery/procedure to the topic Preparation room; and e) exclusion of the item about clinical parameters.

The change in this last item, which was considered by the researchers an important change in the contents of the instrument, led to another evaluation by the three judges who participated in the second stage of the study, and accepted verifying the instrument again. The justification given by the participants in the pre-test for the exclusion was that these parameters are generally already in the trans-operative form, and writing them down again would be nothing but repeated work. The judges accepted the suggestion and, as a result, the item was excluded from the last version.

Therefore, the final version was made up of 43 items, distributed in five topics: eleven in the Heading, eight in Patient admission, ten in Before the start of the surgery/ procedure, eight in Before leaving the operating room, and six in Before leaving the surgical center (Appendix 1).

\section{DISCUSSION}

Considering that surgical procedures expose the patient to risks, the implementation of checklists significantly contributes to avoid adverse events related to healthcare(6).

Authors highlight that elaborating and validating instruments is a complex process, and recommend that this elaboration should only be carried out when no instrument is available that can attend to the needs of the services and/or researchers ${ }^{(15)}$. Therefore, even considering how complex this process is, the authors of this article thought it was essential to create a checklist, considering that the one proposed by the WHO is not entirely adequate for application to patients who are to undergo outpatient surgical procedures, since most of these patients are not hospitalized at the end of the procedure, going back to their homes instead.

After the checklist for outpatient surgical procedures was created, the validation of content was an important stage. At this point, there was a verification to see whether the instrument really measured what it aimed at measuring ${ }^{(14)}$. That is why the recommendation of choosing experts to be the judges was followed, contributing for the evaluation of the relevance and representativity of the items. 
Table 1 - Topics and items of the checklist whose Content Validity Index score was below 0.9 in the first round, in the evaluation of the judges. Campinas, 2018

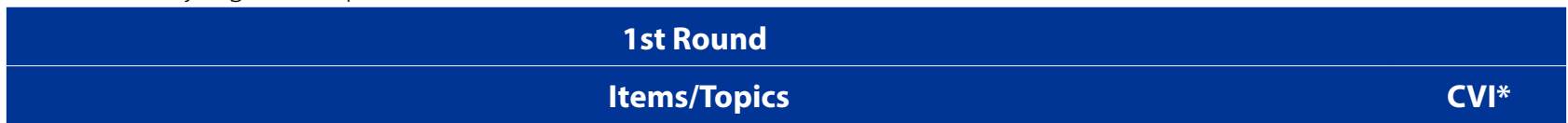

\section{Topics}

$\begin{array}{ll}\text { Reception } & 0.8\end{array}$

$\begin{array}{ll}\text { Medical evaluation } & 0.8\end{array}$

\section{Items}

Specialty

Proposed surgery

Time

Does the patient have a photo ID including name and birth date?

Are patient tags present?

Identification bracelet (with at least two identification elements)?

Signed surgical consent?

Does the patient confirm their name and date of birth is right in the records and tags?

Does the patient inform what surgery is to be conducted?

Does the patient inform where the site of surgery is?

Does the patient have known allergies?

Is the patient fasting?

Are dental prostheses, intimate clothing, ornaments, and others delivered to the person accompanying the patient?

Vital signs

Signed pre-anesthetic visit

Does the patient confirm the name and birth date as it is in the records and tags?

Does the team confirm which surgery is to be carried out?

Does the team confirm the side of the surgical site?

Functioning monitoring?

Do signs confirm that the materials were correctly sterilized?

Anatomical pathology?

Specimens sent to freeze?

Identification and tracking of consigned materials (prostheses, clamps, expanders, and others)?

In the opening of the cage

Before closing

After the surgical team leaves 
The electronic data collection in this stage was a positive point, since it is extremely difficult to schedule a date that is appropriate for all judges, although we do believe that in-person meetings could lead to deeper reflections and contributions. However, this strategy was also used by a research that aimed to elaborate, evaluate, and validate a checklist for surgical safety for the pre- and post-operative stages of surgical hospitalization units. In it, eight judges evaluated the materials using the Delphi technique online $e^{(16)}$.

Considering that the number of judges recommended by literature participated in the study, and that the minimum agreement recommended between the experts should be 0.8 or higher, the authors opted for a stricter rule to define acceptable CVIs, adopting values above 0.9. That was done to better guarantee the relevance and representativity of the contents of each item ${ }^{(14)}$.

The participation of researchers, professors, and professionals from the assistance highly contributed for the improvement of the instrument, making the items clearer. Separating single questions into several ones made it so there were no two questions in a single item, which could prejudice the choice of answers by the target population.

Detailing some items contributes for the professionals to have no difficulties in their interpretation, which was made clear by the absence of comments from the pre-test participants. Regarding the patients, the suggestions of the judges also contributed. They led to the replacement of the expression "surgical site" by "place where the surgery/ procedure will happen", which also led to no questions in the pre-test. In general, as it happened in some previous studies, the judges suggested more changes in the way in which the items were presented than in the content of said items ${ }^{(16)}$.

The topic "Before leaving the surgical center" includes items on following guidance before discharge, delivering surgical reports, among other points. A research has reiterated the need of informing patients on these data, considering the current context of population aging and the presence of multiple morbidities. Therefore, addressing these items before discharge would contribute for the safety of patients, as they would have received information on the plans, and additional signs and symptoms to be observed, as well as on how and when they should seek professional help ${ }^{(17)}$.

The judges asked for the inclusion of the response option "does not apply"(N/A) in many questions because most surgeries carried out in outpatient units do not require opening compress bandage, and in some cases, do not even require the opening of surgical cavities. Researchers state that the nurse, as the manager of the surgical center, is a key piece of the team involved in perioperative assistance ${ }^{(6)}$, and therefore, the item was kept, meaning that, if compress bandages are used, the safety of the patient will not be compromised.
Unlike the checklist from the $\mathrm{WHO}^{(2)}$, at the end of each topic a field was inserted for the identification and registration of the professionals. That was done because different professionals accompany the patients from the reception until they are discharged, be it in elective and emergency surgical centers or in outpatient ones ${ }^{(5)}$.

As highlighted by authors, pre-tests are extremely important to verify whether the population that will answer the instrument considers it understandable ${ }^{(14)}$. Therefore, the considerations made by the professionals who participated in this stage also contributed to improve the instrument.

It should be highlighted that the results from a Spanish study carried out with 105 nurses from the surgical field and 150 patients operated in a tertiary hospital showed an association between the number of adverse events in patients and nurses who were dissatisfied and less committed to their work ${ }^{(18)}$. Therefore, when elaborating research instruments to be used in services, it is important for researchers to get closer to the final users of the instrument, which is done in the pre-test stage and in the implantation of the final version.

Reallocating some items in different topics from the ones where they were initially followed the logic of healthcare that patients who undergo outpatient surgical procedures need in practice. This is in accordance to the needs of professionals who apply these instruments to practical settings, since these are often not thought in accordance to the dynamic of the services ${ }^{(5)}$. In addition, the layout of an instrument collaborates for its greater acceptability and usability ${ }^{(17)}$.

Instruments that work as barriers against adverse events are paramount, but authors have highlighted that their implementation alone does not guarantee changes in the results ${ }^{(15)}$. A study carried out to measure the adherence to the objectives of the program Safe Surgeries Save Lives in Brazilian surgical centers found that, from the perspective of nurses, it is adequate, but there are still events that should never happen (never events). In the case of this study, objectives nine (Effectively communicating and exchanging critical information to safely carry out operations) and ten (The hospital and the public health systems establish routine surveillance on the capacity, volume, and surgical results) presented the lowest agreement values between nurses, with respective results of $81.4 \%$ and $68.2 \%$. This makes it clear that, both in the level of the teams and in an institutional level, communication problems are frequent ${ }^{(19)}$.

As a result, the development of a culture of institutional safety based on planning and continued strategies and evaluations is essential. Additionally, adequate training and guidance for the team with regards to the completion of the checklist, valuing the importance of the instrument, and effective communication between professionals are required for the quality of the assistance to be guaranteed ${ }^{(15)}$. 


\section{CONCLUSION}

The instrument called "Checklist for Safe Surgeries for Outpatient Procedures"was created and its content was validated by judges. In this study, the checklist did not go through clinical validation, limitation that may lead to future researches. Other studies can be carried out aiming at verifying the barriers and/ or challenges in the implementation of the instrument in outpatient surgical procedures, the adherence of professionals to the checklists, and the results met after its implementation.

Making the Checklist for Safe Surgeries for Outpatient Procedures available for the scientific community will allow managers to improve communication between professionals, which will in turn contribute to minimize the number of adverse events, diminish costs, and guarantee the safety and the quality of assistance offered to the patient.

\section{REFERENCES}

1. Vivekananthama S, Ravindrana RP, Shanmugarajah K, Maruthappub M, Shalhoub J. Surgical safety checklists in developing countries. Int I Surg. 2014;12(5):2-6. doi: https://doi.org/10.1016/j.ijsu.2013.10.016

2. World Health Organization (CH). WHO guidelines for safe surgery, 2009: safe surgery saves lives. Geneva: WH0; 2009 [cited 2019 Aug 1]. Available from: https://apps.who.int/iris/bitstream/handle/10665/44185/9789241598552_ eng.pdf;jsessionid=B2D781262C7E26D33992E95EF2BA1020? sequence $=1$

3. Ministério da Saúde (BR). Metas internacionais de Segurança do Paciente: para que as boas práticas estejam por todos os lados. Brasília; [s.d.] [citado 2019 jun 04]. Folder. Available from: https://proqualis.net/sites/proqualis.net/ files/0000024028rNYKH.pdf

4. Ministério da Saúde (BR). Portaria № 529, de 10 de abril de 2013. Institui 0 Programa Nacional de Segurança do Paciente (PNSP). Diário Oficial da União. 2013 abr 02 [cited 2018 Jun 04];150(62 Seção 1):43-4. Available from: http:// www.aeciherj.org.br/docs/portaria-529_2013.pdf

5. Russ SJ, Sevdalis N, Moorthy K, Mayer EK, Rout S, Caris J, et al. A qualitative evaluation of the barriers and facilitators toward implementation of the WHO surgical safety checklist across hospitals in England lessons from the "Surgical Checklist Implementation Project". Ann Surg. 2015;261(1):81-91. doi: https:// doi.org/10.1097/SLA.0000000000000793.

6. Tostes MFP, Galvão MC. Implementation process of the surgical safety checklist: integrative review. Rev Latino-Am Enfermagem. 2019;27:e3104. doi: https:// doi.org/10.1590/1518-8345.2921.3104

7. White MC, Randall K, Capo-Chichi NFE, Sodogas F, Quenum S, Wrigh K, et al. Implementation and evaluation of nationwide scale-up of the Surgical Safety Checklist. BJS Open. 2019;106(2):e91-e102. doi: https://doi.org/10.1002/bjs.11034
8. Santos J, Sankarankutty A, Salgado Jr W, Kemp R, Leonel E, Castro e Silva Jr 0. Cirurgia ambulatorial: do conceito à organização de serviços e seus resultados. Medicina (Ribeirão Preto). 2008;41(3):274-86. doi: http://www.revistas.usp. $\mathrm{br} / \mathrm{rmrp} / \mathrm{article} / \mathrm{view} / 273$

9. Viswanath A, BalintA, Johnson RE, Rosenberg MB,Oread D. Surgical Safety Checklists are underutilized in ambulatory oral and maxillofacial surgery. J Oral Maxillofac Surg. 2018;76(2):267-72. doi: https://doi.org/10.1016/j.joms.2017.07.154

10. Molina G, Singal R, Haynes AB, Mahishi V, Davis KK, Foster G, et al. Perception of safety ofsurgical practiceamonghealthcareprofessionalswhoworkinanoperating room in ambulatory surgery centers in the United States: a retrospectiveanalysis of survey data. Perioper Care Oper Room Manag. 2017;8:12-8. doi: https://doi.org/ 10.1016/j.pcorm.2017.07.002

11. Treadwell JR, Lucas S, Tsou AY. Surgical checklists: a systematic review of impacts and implementation. BMJ Qual Saf. 2014;23(4):299-318. doi: https://doi. org/10.1136/bmjqs-2012-001797

12. Cadman V. The impact of surgical safety checklists on theatre departments: a critical review of the literature. J Perioper Pract. 2016;26(4):62-71. doi: https:// doi.org/10.1177/175045891602600402

13. Alexandre NMC, Coluci MZO. Validade de conteúdo nos processos de construção e adaptação de instrumentos de medidas. Cienc Saude Coletiva. 2011;16(7):30618. doi: https://doi.org/10.1590/S1413-81232011000800006

14. Coluci MZO, Alexandre NMC, Milani D. Construção de instrumentos de medida na área da saúde. Cienc Saude Coletiva. 2015;20(3):925-36. doi: https://doi. org/10.1590/1413-81232015203.04332013

15. Tang R, Ranmuthugala G, Cunningham F. Surgical safety checklists: a review. ANZ J Surg. 2014;84(3):148-54. doi: https://doi.org/10.1111/ans. 12168

16. Alpendre FT, Cruz EDA, Dyniewicz AM, Mantovani MF, Silva AEBC, Santos GS. Safe surgery: validation of pre and postoperative checklists. Rev Latino-Am Enfermagem. 2017;25:e2907. doi: https://doi.org/10.1590/1518-8345.1854. 2907

17. Fernando RJ, Shapiro FE, Urman RD. Survey analysis of an ambulatory surgical checklist for patient use. AORN J. 2015;102(3):290.e1-10. doi: https://doi. org/10.1016/j.aorn.2015.07.013

18. Sillero-Sillero A, Zabalegui A. Safety and satisfaction of patients with nurse's care in the perioperative. Rev Latino-Am Enfermagem. 2019;27:e3142. doi: https://doi.org/10.1590/1518-8345.2646.3142

19. GutierresLS,Santos JLG, BarbosaSFF,MaiaARC, KoerichC, Gonçalves N. Adherence to the objectives of the Safe Surgery Saves Lives Initiative: perspective of nurses. Rev Latino-Am Enfermagem. 2019;27:e3108. doi: https://doi.org/10.1590/ 1518-8345.2711.3108

\section{Acknowledgement:}

To the Institutional Program of Scientific Initiation Scholarships - National Council of Technological and Scientific Development, for the scholarship received.

\section{- Corresponding author:}

Renata Cristina Gasparino

E-mail: grenata@unicamp.br

\section{Associate editor: \\ Wiliam Wegner}

\section{Editor-in-chief:}

Maria da Graça Oliveira Crossetti 


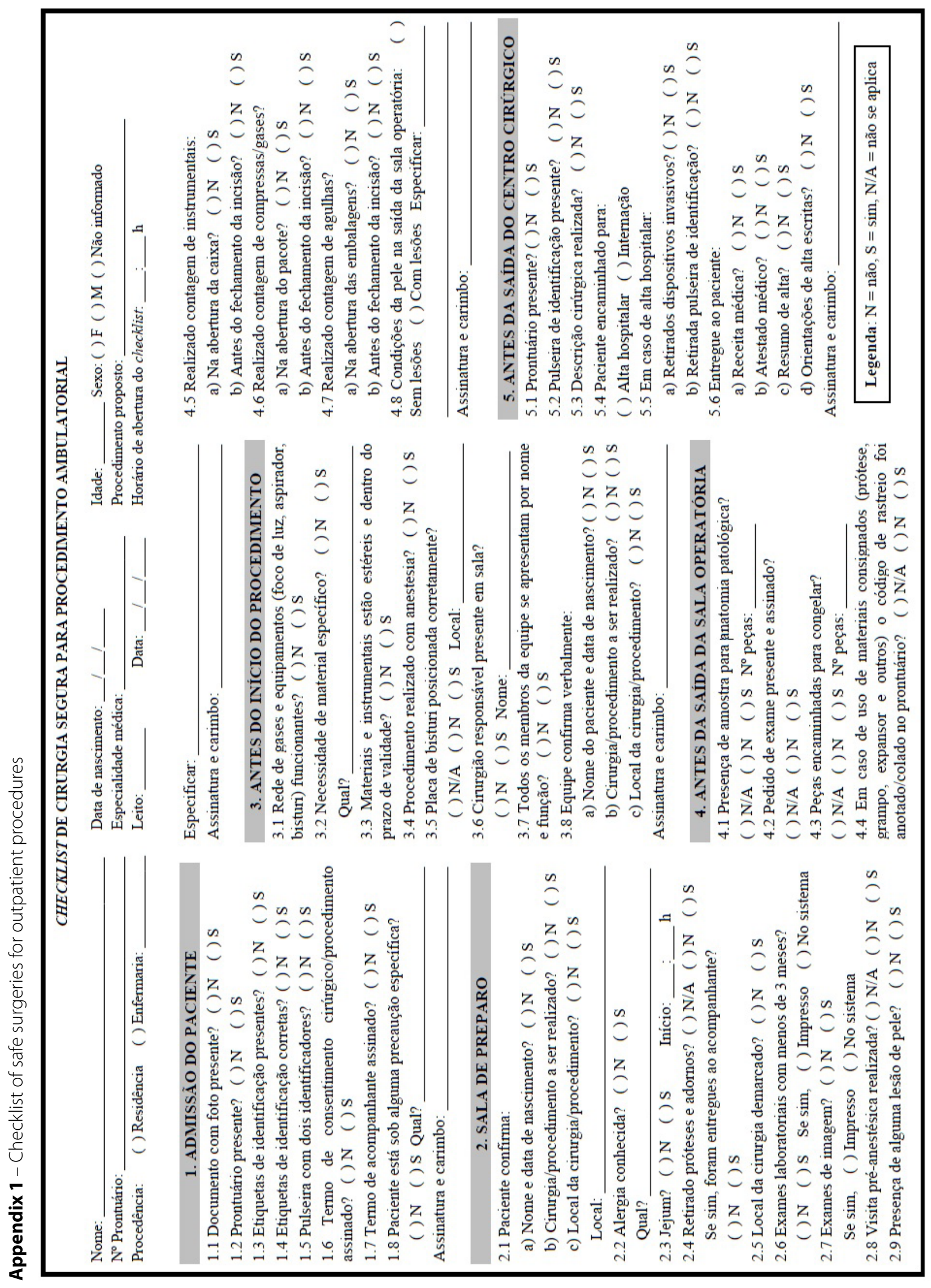

